\title{
Proposal of enhanced treatment process based on actual pilot plant for removal of micropharmaceuticals in sewage treatment plants
}

\author{
Shun-hwa Lee ${ }^{1}$, Yun-kyung Park ${ }^{1}$, Miran Lee ${ }^{2}$, Byung-dae Lee ${ }^{3+}$ \\ ${ }^{1}$ Department of Environmental Engineering, Yeungnam University, Gyeongsan 38541, Republic of Korea \\ ${ }^{2}$ Daisung Green Tech 601ho, 537 Dunchon-daero, Jungwon-gu, Seongnam-si, Gyeonggi-do, Republic of Korea \\ ${ }^{3}$ Department of Health Management, Uiduk University, Gyeongju 38004, Republic of Korea
}

\begin{abstract}
This study was carried out to increase the treatment efficiency through the improvement of the conventional biological process, and to propose the optimal treatment direction. The optimal treatment conditions were derived based on the results of the spike damage tests in each single process. The removal efficiency of micropharmaceuticals was further increased when an ozone treatment process was added to the biological process compared to the single process. The soil and activated carbon adsorption process was introduced in the post-treatment to remove the micropharmaceutical residues, and the removal efficiency of the pharmaceduticals in the final effluent was more than $85 \%$ in spike damage experiment. In particular, the continuous process of biological treatment-ozone-adsorption could ensure the stable treatment of micropharmaceuticals, which had not been efficiently removed in the single process, as it showed more than $80 \%$ removal efficiency. Therefore, it is expected that the addition of the ozone oxidation and activated carbon adsorption process to the existing sewage treatment facilities can contribute to the efficient removal of micropharmaceuticals.
\end{abstract}

Keywords: Activated carbon, Micropollutants, Ozone, Pharmaceuticals

\section{Introduction}

World Health Organization (WHO) predicted that chronic diseases like hypertension, diabetes, and arthritis will account for $70 \%$ of the world's diseases in the 2020s. The reason for this is that the global pharmaceuticals market has grown over the past 7 years, with an annual average growth rate of $5.2 \%$ from 2010 to 2016 , when it was worth US\$1,104.2 billion, with a $4.9 \%$ increase from the previous year [1]. In South Korea, the pharmaceutical production amounted to 18.81 trillion won in 2017 , showing a $10.8 \%$ increase from the previous year, and tended to grow, with an annual average increase of $3.1 \%$ for the past 5 years [2].

Especially in South Korea, the psychological dependence on medications is high, and medication overuse and drug abuse often occur. As a result, $30-90 \%$ of drugs, which are not metalized, are excreted in urine, and expired pharmaceuticals are buried in landfills, so that the amount of pharmaceuticals introduced into the soil or sewage increases and finally enters the groundwater or natural water system, thereby having an adverse effect on the living environment [3]. It has been reported that the antibiotic prescription rate of South Korea is about $59 \%$, which is more than twice that of WHO (23\%), and there is a growing concern about environmental hazards due to micropharmaceuticals [4]. In addition, the released pharmaceuticals enter the aquatic ecosystem, leading to bioaccumulation and toxicity [5]. Meanwhile, the effluent from sewage treatment plants has been reported to be the main cause of the introduction of most pharmaceuticals into the aquatic environment, so the removal of micropharmaceuticals in sewage treatment plants is considered very important.

As more than $95 \%$ of the domestic sewage treatment plants that are currently in operation, however, use the conventional biological treatment processes, they pose limitations in removing micropollutants like pharmaceuticals. Therefore, it is urgent to enhance the treatment efficiency by complementing and improving
This is an Open Access article distributed under the terms of the Creative Commons Attribution Non-Commercial License (http://creativecommons.org/licenses/by-nc/3.0/) which permits unrestricted non-commercial use, distribution, and reproduction in any medium, provided the original work is properly cited.

Copyright (C) 2020 Korean Society of Environmental Engineers
Received June 10, 2019 Accepted August 23, 2019

${ }^{\dagger}$ Corresponding author

Email: bdlee@uu.ac.kr

Tel: +82-54-760-1702 Fax: +82-54-760-1179

ORCID: 0000-0002-0792-1924 


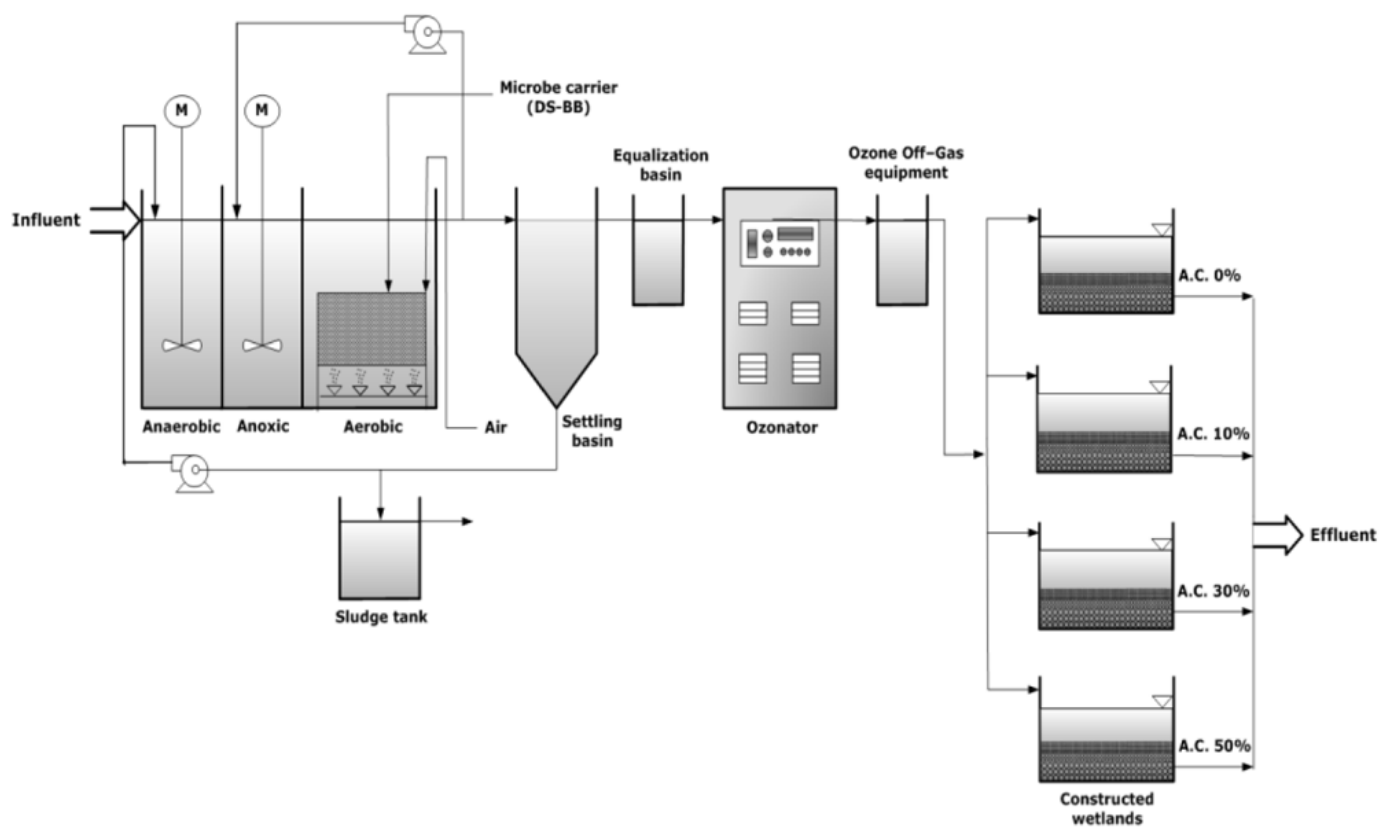

Fig. 1. System configuration of the actual pilot plant.

the currently used biological processes. There have been reports on the treatment efficiency of pharmaceuticals in municipal sewage using ozone oxidation and activated carbon adsorption [6-7]. There was also a literature on estimating the amount of ozone needed to remove $\mathrm{P}$ in wastewater treatment plant effluents [8]. However, few literatures have reported the removal efficiency by spiking pharmaceuticals artificially on actual pilot plants. In this study, a comparative analysis of the variations in the concentrations of micropharmaceuticals was conducted on the public sewage treatment plants in K City. In addition, the removal efficiency of micropharmaceuticals was investigated through the pilot plant of the biological treatment-ozone-activated carbon process. As of 2016, K City has a sewage population of 243,372 , and the sewage treatment facility has a capacity of $40,000 \mathrm{~m}^{3} / \mathrm{d}$, with a treatment efficiency of $99.5 \%$ [9]. It uses a two-stage anaerobic-anoxic-aerobic treatment process [10], and in the case of the standard city sewage, the total nitrogen removal efficiency is $60-70 \%$, and the total phosphorus removal efficiency is $70-80 \%$ [11] with respect to the primary sedimentation tank effluent.

As shown in Fig. 1, the pilot plant was constructed with a 100 $\mathrm{m}^{3} / \mathrm{d}$ capacity for research purposes, to improve the biological treatment efficiency and increase the removal efficiency of micropharmaceuticals. The internal recycling ratio was $150 \%$, and the MLSS concentrations in all units (i.e., anaerobic, anoxic, and aerobic) were maintained at 3,000 $\mathrm{mg} / \mathrm{L}$ and 4,000 $\mathrm{mg} / \mathrm{L}$ in summer and winter season, respectively. The configuration of its system was the same as that of the public sewage treatment plant in $\mathrm{K}$ City, and the primary sedimentation tank effluent through the equalization tank was used for the operation of the influent of the pilot plant. The bioreactor of the pilot plant was operated as a process with higher treatment efficiency than that of the onsite treatment plant through the introduction of a carrier, which is reported to have higher organic substance removal efficiency [12] than the general biological process. In addition, as the use of the biological treatment alone has limitations in the removal of micropharmaceuticals, the oxidation and adsorption processes using ozone and activated carbon were additionally introduced to analyze the samples by process.

In this regard, this study analyzed the monthly variations in the concentrations of pharmaceuticals in sewage treatment plants. In addition, a pilot plant to which physical and chemical processes were added was installed, and spike damage tests were conducted to evaluate the characteristics of the micropharmaceuticals treatment. The treatment characteristics of the biological treatment, ozone, and adsorption process were also examined to present data for the directions of treatment process improvement and water quality management in sewage treatment plants.

\section{Research Contents and Method}

\subsection{Target Pharmaceuticals}

In this study, micropharmaceuticals, which are frequently detected in domestic sewage treatment plants and river water, were selected considering the pharmaceuticals that are under study in other countries, including USA and UK, and the results of the survey conducted by the National Institute of Environmental Research in South Korea. The substances under research contain a total of five pharmaceuticals, including two kinds of anti-inflammatory drugs (acetaminophen, diclofenac), two kinds of antibiotics (sulfamethoxazole, trimethoprim), and one kind of antiepileptic drug (carbamazepine).

\subsection{Analysis and Experiment Methods}

The samples for each process were collected and analyzed after 
the installation of the pilot plant. For the sampling of pharmaceuticals, brown glass bottles were used to prevent deterioration, and they were washed with acetone once, and ascorbic acid was added at a concentration of $1 \mathrm{~g} / \mathrm{L}$. Immediately after sampling, the samples were kept at $4^{\circ} \mathrm{C}$ in a cooling box, and were analyzed via liquid chromatography/mass spectrometry (LC-MS/MS). The analytical conditions of the pharmaceuticals are summarized in Table S1 and other influent water qualities are shown in Table S2.

\subsection{Test Equipment Configuration}

\subsubsection{Ozone test equipment}

The ozone generators used in the actual pilot plant $\left(100 \mathrm{~m}^{3} / \mathrm{d}\right)$ are OE's OZW30 models. The ozone concentration arising from the ozone generator was basically maintained at a voltage of 1 $\mathrm{kg} / \mathrm{cm}^{2}$ and an air flow rate of $30 \mathrm{~L} / \mathrm{min}$, and then the ozone concentration in the water was analyzed to adjust each ozone concentration to the oxygen inflow rate. The ozone concentrations were analyzed with KI solution using ozone demands flask [13].

\subsubsection{Adsorption process configuration}

The adsorption process was installed at the end of the ozone treatment process, and consisted of four basins. This process is a method for adsorbing and decomposing the micropollutants in water with the use of soil filtration and microorganisms. To cultivate the microorganisms, the experiment was conducted after passing effluent for the initial 20 days or more to form a biofilm.

In this experiment, 5-10 $\mathrm{mm}$ gravel and 2-5 $\mathrm{mm}$ and 0.8-1.2 $\mathrm{mm}$ sand were used as filter media. In response to the low treatment efficiency of a single process using soil microorganisms, the granular activated carbon was mixed at the soil volume ratios of 10,30 , and 50\%. The charcoal-based granular activated carbon adopted an $8 \times 30$ mesh with a $5 \%$ or less moisture content and $95 \%$ or more hardness. The size of each basin was $1 \times 1 \times 1.2 \mathrm{~m}$, and a detention basis with a $1.2 \mathrm{~m}^{3}$ volume was built. The empty bed contact time (EBCT) was adjusted to 7-20 min.

\section{Results and Discussion}

\subsection{Variations in the Monthly Concentrations of the Pharmaceuticals}

The variations in the pharmaceutical concentrations in the influent from the sewage treatment plants in K City are shown in Fig. S1, and the removal efficiencies in final effluent are summarized in Table S2. The average concentration of acetaminophen in the influent was $30.3 \mu \mathrm{g} / \mathrm{L}$, and that in the effluent was $0.013 \mu \mathrm{g} / \mathrm{L}$, which indicates that its removal efficiency was 99.95\%. Acetaminophen is known to be used more frequently than other pharmaceuticals because it is an over-the-counter medicine available from pharmacies. Therefore, its concentration introduced into sewage is considered higher than that of other pharmaceutical substances. The octanol/water partition coefficient (log $\mathrm{K}_{\mathrm{ow}}$ ) of acetaminophen is 0.4. It has been reported that it is difficult to remove hydrophilic micropollutants with $\log \mathrm{K}_{\mathrm{ow}}<1$ as they are adsorbed on sludge, but they can be combined with coagulants in the anionic state depending on the $\mathrm{pH}$ condition [14]. Therefore, it was con- cluded that although the influent concentration of acetaminophen was high, it was treated efficiently in each sewage treatment plant using coagulants, and then discharged into the natural water system. In addition, it is a substance that is easily dissolved in water and that influences the water quality because its solubility is as high as $14,000 \mathrm{mg} / \mathrm{L}$. It has been reported, however, to be rapidly removed by various physicochemical reactions (biodegradation, hydrolysis, oxidation, etc.) [15]. Meanwhile, acetaminophen, a common analgesic and antipyretic, is also used throughout the year for a variety of colds and influenza medications. It showed the highest concentration especially in December, during the winter season [16].

In the case of carbamazepine, its average concentration in the influent was $0.091 \mu \mathrm{g} / \mathrm{L}$, and that in the effluent was $0.090 \mu \mathrm{g} / \mathrm{L}$, indicating that its removal efficiency was $-6.02 \%$ on average. The research results showed that carbamazepine exhibits a very rapid metabolic response in the human body, but it is very stable in the aquatic environment $[17,18]$. It has also been reported that $72 \%$ of it is adsorbed even when metabolized, and the remainder is released as it is $[19,20]$. In addition, as it is a medicinal substance that is used as an antiepileptic agent or a psychotherapeutic agent for the treatment of bipolar disorder and is thus consumed steadily throughout the year, it showed no distinct variations in the monthly influent concentrations.

For sulfamethoxazole, it was introduced at a mean concentration of $0.03 \mu \mathrm{g} / \mathrm{L}$ and was discharged at a mean concentration of 0.07 $\mu \mathrm{g} / \mathrm{L}$, which indicates that its removal efficiency was $-136.96 \%$ on average. Like acetaminophen, it has a $\log \mathrm{K}_{\text {ow }}$ value of less than 1 (i.e., 0.68), and thus, it is likely to be combined with cationic compounds in water due to its characteristic of being able to sustain anions at $\mathrm{pH} 7$ or more. It showed a tendency to have a higher effluent concentration, however, because sulfonamide metabolites introduced into the sewage are biologically inactive $\mathrm{N}_{4}$-acetylated products and return to the original active compounds during sewage treatment. In this connection, it has been reported that sulfonamide in the biological sewage treatment process leads to a negative (-) removal action, and thus, a similar case is also found in methoxazole [4]. In addition, as sulfamethoxazole is a medicinal substance used for the treatment of urinary tract infection, there are no seasonal changes in its concentrations.

The average concentration of trimethoprim in the influent was $0.028 \mu \mathrm{g} / \mathrm{L}$, and that in the effluent was $0.020 \mu \mathrm{g} / \mathrm{L}$, indicating that its removal efficiency was $8.35 \%$ on average. It is known that the adsorption efficiency of residual pharmaceuticals with amine group $\left(\mathrm{NH}_{2}\right)$ is high $[17,21]$. Therefore, the removal efficiency of trimethoprimwith two amino groups $\left(\mathrm{NH}_{2}\right)$ was expected to be relatively higher than that of other pharmaceuticals, but the public sewage treatment plant in K City showed low removal efficiency. This is because the non-degradable materials present in the sewage affected the removal of micropharmaceuticals, and the biological retention time in the anaerobic-anoxic-aerobic process was less than 6 hours, shorter than that of other processes. Trimethoprim is a type of antibiotic mainly used for the treatment of respiratory system and urinary tract infections, and thus showed no seasonal changes in concentration as it is taken for a certain period of time.

In the case of diclofenac, it was introduced at a average concentration of $0.09 \mu \mathrm{g} / \mathrm{L}$ and was discharged at a mean concentration 
of $0.14 \mu \mathrm{g} / \mathrm{L}$, which indicates that its removal efficiency was $-60.78 \%$ on average. Other studies have also reported that it showed a negative (-) removal efficiency, which can be due to various factors, such as the hydrolysis of the drug conjugates [22]. As diclofenac is used as an analgesic and antipyretic drug, it showed the highest concentration in December, during the winter season.

\subsection{Spike Damage Test}

The pilot plant was used to investigate the removal effects of organic substances and nutrients and to stabilize the system, and then spike damage tests were conducted on pharmaceuticals. The standard reagents were purchased or manufactured to examine the removal efficiency of micropharmaceuticals by the biological treatment process and by the ozone and activated carbon process.

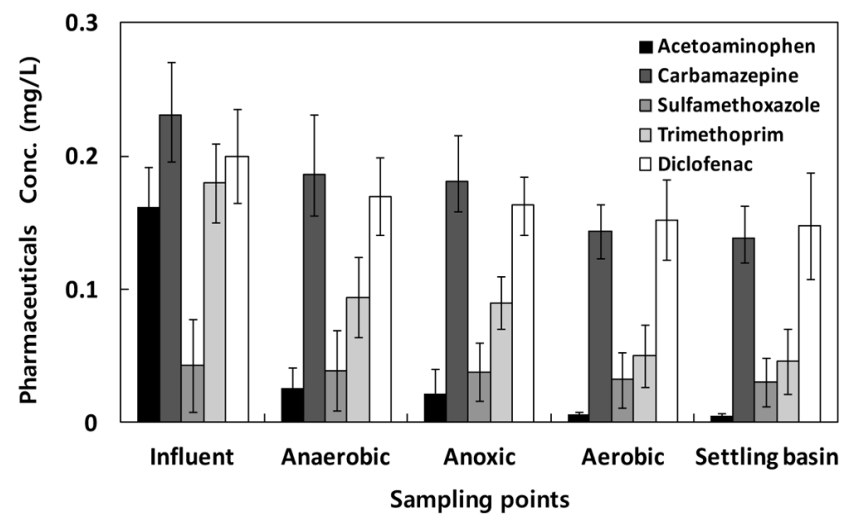

Fig. 2. Variations in the pharmaceuticals concentrations by biological treatment (acetaminophen conc. $\times 10$ ).

\subsubsection{Removal efficiency by the biological treatment process}

The variations in the concentrations due to the biological treatment process in the spike damage tests are shown in Fig. 2. In the case of acetaminophen, the removal efficiency by the biological treatment process of the pilot plant was as high as $95 \%$ or more, similar to the above. The trimethoprim removal efficiency was $74.4 \%$, the carbamazepine removal efficiency was $40.3 \%$, the sulfamethoxazole removal efficiency was $30.2 \%$, and the diclofenac removal efficiency was $26.0 \%$. Overall, the pharmaceuticals tended to be removed somewhat through the bioreactor. The results obtained after injecting artificially high levels of concentrations were found to be different from those obtained from the removal efficiency review tests by process. This suggests that removal effects occur even in the biological treatment process. The removal efficiencies of carbamazepine, sulfamethoxazole, and diclofenac, however, were still lower than $50 \%$.

In the biological treatment process, microorganisms grow in a suspended state in the wastewater, and various pollutants are made into organic substances and then converted to new cells or final products. In this case, the removal efficiency of pharmaceuticals, which are high molecular substances, is low due to the slow decomposition rate [23]. As a result, acetaminophen, with a molecular mass of $151.2 \mathrm{~g} / \mathrm{mol}$, the smallest among the target pharmaceuticals, has the highest treatment efficiency. In the case of trimethoprim, it has a large molecular mass $(290.3 \mathrm{~g} / \mathrm{mol})$ but exhibits relatively high removal efficiency due to its two amino groups $\left(\mathrm{NH}_{2}\right)$ with high adsorption efficiency. The molecular masses of carbamazepine and sulfamethoxazole are 236.3 and $253.3 \mathrm{~g} / \mathrm{mol}$, respectively, and their biological treatment removal efficiencies by microorganisms are similar to each other due to their similar physical properties, as both of them have only one amino group $\left(\mathrm{NH}_{2}\right)$ [24]. Diclofenac has the largest molecular mass (296.2 g/mol) among the five pharmaceuticals, and it has no amino group $\left(\mathrm{NH}_{2}\right)$, thus having the lowest treatment efficiency.

It has been reported that because most of the pharmaceuticals are aromatic compounds, which have complex structures and are often polymeric, they cannot be efficiently treated by the existing biological treatment methods using microorganisms [25]. Therefore, the method using a powerful oxidizing agent like ozone is expected to increase the removal efficiency of micropharmaceuticals by transforming non-degradable compounds with complex structures and strong binding forces into low-molecular compounds.

\subsubsection{Comparison of the removal efficiencies of the spike damage test and the biological treatment process in the actual sewage treatment plant}

The comparison results of the removal efficiency obtained by the biological treatment process of the actual sewage treatment plant and that obtained by the spike damage test are shown in Fig. 3(a) and (b).

The tendency of the removal efficiency by the biological treatment process is represented by slope $\mathrm{K} 1$, and that by the spike damage test is represented by slope K2. As shown in Fig. 3(a), the K1 value was -0.1621 for acetaminophen, and the $\mathrm{K} 2$ value was -1.4135 . These results suggest that the speed of removal is higher in the spike damage test even at similar removal efficiency, and thus, large amounts are removed in a relatively short time. It was found that when micropharmaceuticals are present in the biological treatment process, they can be almost completely removed by the treatment for 6 hours. In addition, they tend to be removed by degree in a shorter time than when high concentrations of pharmaceuticals are present. This tendency is similar to the case where the number of organic matters is reduced by microorganisms in the $\mathrm{A}_{2} / \mathrm{O}$ bioreactor, and acetaminophen is expected to be removed by the biological treatment process. In addition, when four micropharmaceuticals are present (K1), a complex matrix effect occurs in the substance present in the influent, and thus, the value of the slope is positive (+). Therefore, it is difficult to accurately evaluate the removal characteristics of micropharmaceuticals. According to the results of the spike damage test, the $\mathrm{K} 2$ values were -0.0109 for carbamazepine, -0.0016 for sulfamethoxazole, -0.0149 for trimethoprim, and -0.0058 for diclofenac, showing clear removal efficiencies, and these results indicate the possibility of removal in the biological treatment process. In addition, as these pharmaceuticals showed relatively higher concentrations of residual substances in the effluent of the bioreactor than acetaminophen, while the slope of the removal efficiency is low, the biological treatment process alone is expected to pose difficulties in removing most of the pharmaceuticals. This means that it can take some time for microorganisms to decompose the pharmaceuticals. Therefore, to remove then effectively in a shorter time, it is desirable to introduce an additional removal process at the end of the biological treatment process. 

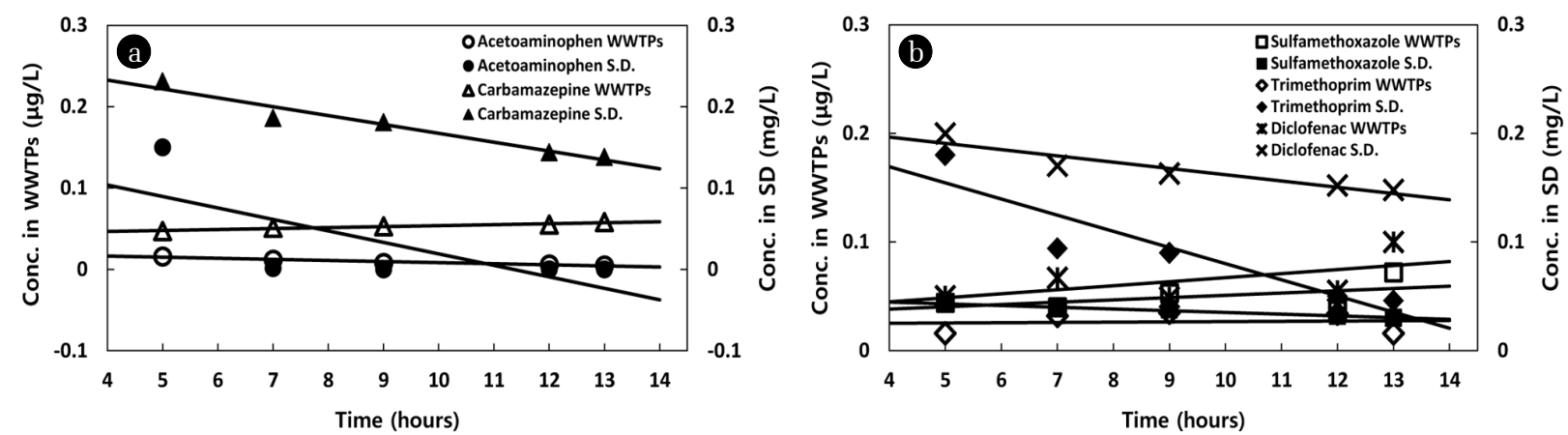

Fig. 3. Removal efficiency of various pharmaceuticals in the spike damage test. (a) Removal efficiency of acetoaminophen and carbamazepine in the spike damage test. (b) Removal efficiency of sulfamethoxazole, trimethoprim and diclofenac in the spike damage test.

\subsubsection{Removal of micropharmaceuticals by the ozone treatment process}

The ozone degradation pathway of acetaminophen, a representative of pharmaceuticals, has been reported. The intermediates follow typical phenol ozonation pathways, such as hydroxylation of phenol ring, anomalous ozonation to cleave aromatic ring of hydroquinone, and decarboxylation by hydroxyl radicals [26]. In addition, it was suggested the acid-catalyzed hydrolysis of amidic intermediates to occur [26, 27]. Meanwhile in the sewage treatment process, ozone is applied to the sewage after the primary sedimentation so that the organic matter can be oxidized first to facilitate the oxidation of organic substances and pharmaceuticals in the biological treatment process. This process has disadvantages, however, in that the vitality of the microorganisms is highly likely to be lowered due to the removal of most of the biodegradable organic substances in the advanced oxidation process, and the maintenance costs rise as many organic substances react with the ozone oxidation [28]. In this regard, in this study, the removal efficiencies by the ozone treatment process were examined using the effluent after the biological treatment process. The ozone concentrations of the ozone generator were measured, and the dissolved ozone concentrations of the aqueous solution were changed to 1,3 , and $5 \mathrm{mg} / \mathrm{L}$. The variations in the concentrations by ozone dosage are shown in Fig. 4.

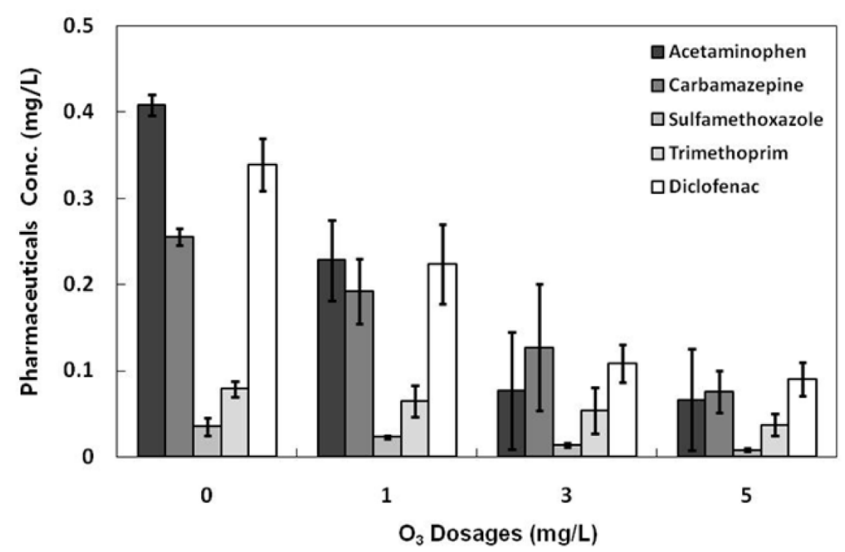

Fig. 4. Variations in the pharmaceuticals concentrations by $\mathrm{O} 3$ dosage (acetaminophen conc. $\times 4$ ).
The purpose of introducing ozone in the sewage treatment plant is to remove the color or the non-degradable organic compounds, and the typical dosage of ozone is $3-6 \mathrm{mg} / \mathrm{L} \mathrm{[28].} \mathrm{In} \mathrm{this} \mathrm{study,}$ when the ozone dosages were 1,3 , and $5 \mathrm{mg} / \mathrm{L}$, acetaminophen showed the highest removal efficiencies of 56.8, 97.9, and $98.3 \%$, respectively, and the removal efficiencies of carbamazepine were $41.9,79.6$, and $80.8 \%$. In addition, the sulfamethoxazole removal efficiencies were 53.3, 64.4, and 86.7\%; the trimethoprim removal efficiencies were $32.9,61.4$, and $65.7 \%$; and the diclofenac removal efficiencies were 52.0, 76.7, and 80.8\%. The removal efficiencies of the five pharmaceuticals selected in this study tended to increase as the ozone dosages increased. As shown in Fig. 5, however, the concentration variation was most markedly decreased at the ozone dosage of $3 \mathrm{mg} / \mathrm{L}$. Thus, $3 \mathrm{mg} / \mathrm{L}$ was determined as the optimal dosage for economical maintenance. These findings were obtained from three or more experiments during the research period, and they were consistent with the reported results of the laboratory tests in the previous studies [30]. Therefore, when the ozone dosage was $3 \mathrm{mg} / \mathrm{L}$, acetaminophen showed the highest removal efficiency, followed by carbamazepine and diclofenac and then sulfamethoxazole and trimethoprim.

Previous studies have reported that the reactivity of residual pharmaceuticals with ozone is related to the radicals and benzene rings [29]. Acetaminophen consists of a single aromatic carbon

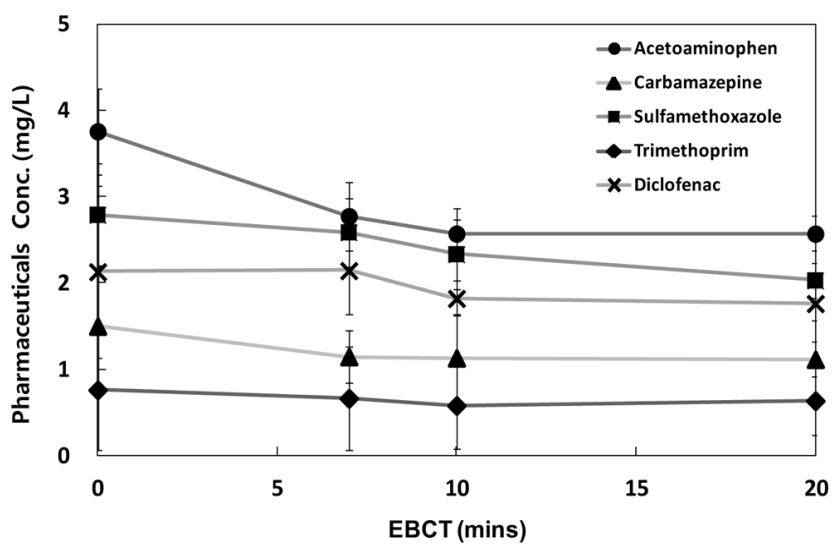

Fig. 5. Variations in the pharmaceuticals concentration by EBCT (acetaminophen conc. $\times 5$ ). 
ring and is smaller in molecular mass and harder to decompose than the other four pharmaceuticals, resulting in higher treatment efficiency by ozone oxidation. In addition, Huber et al. reported that the reaction of $\mathrm{OH}$ radicals with carbamazepine, diclofenac, and sulfamethoxazole was 2-3 times faster in ozone treatment. Thus, ozone treatment can be applied as an effective method for removing pharmaceuticals [29, 31]. In the relevant studies in South Korea, the concentration of trimethoprim was reduced by $33.5 \%$ to the residual concentration of $6.65 \mu \mathrm{g} / \mathrm{L}$ at an ozone dosage of $1 \mathrm{mg} / \mathrm{L}$, by $78.6 \%$ to the residual concentration of $2.14 \mu \mathrm{g} / \mathrm{L}$ at an ozone dosage of $2 \mathrm{mg} / \mathrm{L}$, and by $88.9 \%$ to the residual concentration of $1.11 \mu \mathrm{g} / \mathrm{L}$ at an ozone dosage of $3 \mathrm{mg} / \mathrm{L}$. In addition, the removal efficiency was $99 \%$ or more, which is below the detection limit, at the ozone dosages of 5 and $8 \mathrm{mg} / \mathrm{L}$. In addition, the removal efficiency of micropharmaceuticals has been reported to be lower in the case of solutes containing organic substances than in the case of pure water solutes [32]. Therefore, it is considered that the low removal efficiencies in this study were due to the differences in solutes, and the introduction of an additional process is required to treat micropharmaceuticals, which are not removed by the ozone treatment process in the present sewage treatment plants. In this regard, there is a need to introduce an adsorption process using activated carbon after the ozone treatment process.

\subsubsection{Removal of micropharmaceuticals by adsorption} 3.2.4.1. Variations in the removal efficiencies by EBCT The results of the experiment designed to determine the optimal EBCT for the adsorption process are shown in Fig. 6. To investigate the changes in the treatment efficiencies according to EBCT, soil without granular activated carbon was used, and the EBCT was adjusted to $7,10,15$, and $20 \mathrm{~min}$ at temperatures of $26-28^{\circ} \mathrm{C}$. The experiment results showed that acetaminophen had a removal efficiency of 26.2-31.6\%; carbamazepine, 23.7-25.7\%; sulfamethoxazole,7.3-27.3\%; trimethoprim,12.9-16.6\%; and diclofenac,-0.7-17.3\%. The treatment efficiencies of the five pharmaceuticals selected in this study showed a tendency to increase with increasing contact time with the activated carbon. As it was difficult to expect higher removal efficiency after $10 \mathrm{~min}$, however, a 10-min EBCT was set as the optimal EBCT, which was consistent with the standard EBCTs of 10-15 min recommended by the U.S.

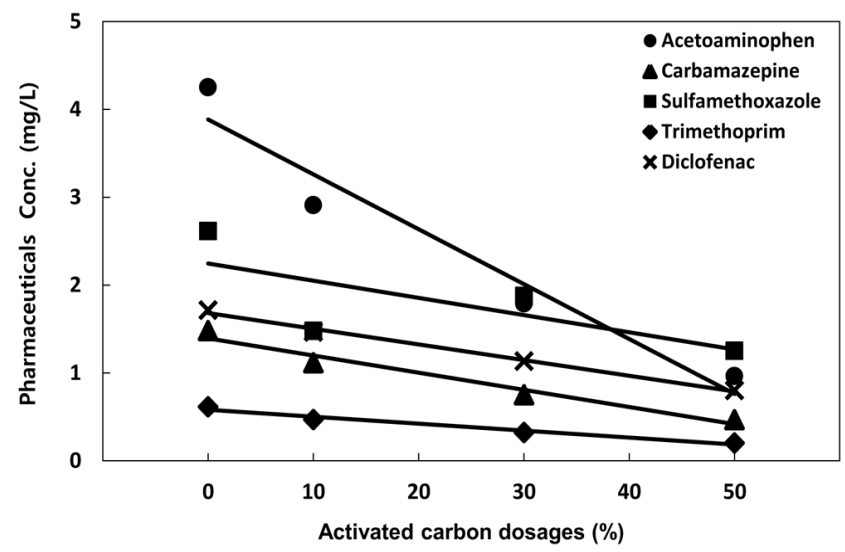

Fig. 6. Variations in the pharmaceuticals concentrations by activated carbon dosage (\%) (acetaminophenconc. $\times 4$ ).
Environmental Protection Agency (USEPA) [33-35]. The removal efficiency of acetaminophen was the highest, and the carbamazepine and trimethoprim removal efficiencies were 24.7 and $23.8 \%$. The removal efficiencies of sulfamethoxazole and diclofenac were 16.4 and $14.5 \%$, respectively.

\subsubsection{Variations in the removal efficiencies by activated carbon dosage}

The results of the experiment conducted on a fixed-bed detention basin using soil microorganisms and on four fixed-bed detention basins incorporating granular activated carbon at 10,30 , and $50 \%$ are shown in Fig. 6. The activated carbon was injected at 0, 10, 30, and 50\% after the EBCT was fixed at $10 \mathrm{~min}$. When the activated carbon dosage was $30 \%$, acetaminophen showed the highest removal efficiency (58\%), followed by carbamazepine (49\%), trimethoprim (48\%), diclofenac (34\%), and sulfamethoxazole (28\%). The treatment efficiencies of all the five pharmaceuticals selected in this study tended to increase with increasing mixing ratio of the granular activated carbon. As the concentration applied to the actual treatment plant was less than $60 \%$, however, which ensures that the residual concentration does not affect the ecosystem, the appropriate dosage was determined to be $30 \%$.

In general, $\log \mathrm{K}_{\mathrm{ow}}$ is used to examine the removal efficiency by adsorption of activated carbon, and EPA is used to predict the qualitative removal of substances during the wastewater treatment, and to provide important information for the removal of micropharmaceuticals, such as the water solubility, soil adsorption, and biological adsorption [15]. Therefore, the results of this study were analyzed based on the above.

The removal efficiency of acetaminophen was high even in the biological treatment process because it ensures high solubility and has easily oxidized properties [15], as shown in section 3.1. Clara et al. reported that carbamazepine did not undergo any decomposition or adsorption while passing through groundwater [36], and Stamatelatou et al. argued that removal by adsorption is more likely to occur in soils with an organic content of $10 \%$ or more than those with a $1-2 \%$ organic content [21, 37]. Rogers categorized the adsorption capacities against the hydrophilic and hydrophobic properties of micropharmaceuticals in three stages: low adsorption capacity ( $\log \mathrm{K}_{\mathrm{ow}}<2.5$ ), intermediate adsorption capacity $\left(\log \mathrm{K}_{\mathrm{ow}}\right.$ $>2.5$ and $<4.0$ ), and high adsorption capacity $\left(\log \mathrm{K}_{\mathrm{ow}}>4.0\right.$ ) [38], and the $\log \mathrm{K}_{\mathrm{ow}}$ of carbamazepineis 2.47, indicating a low adsorption capacity. Therefore, it is difficult for carbamazepine to be adsorbed on suspended solids and removed in the actual sewage treatment plant and pilot plant, which are the subjects of this study.

In this study, sulfamethoxazole showed the lowest removal efficiency with respect to the activated carbon dosage, and this result was similar to that in the European Union (EU) report that although the activated carbon adsorption process is a very effective treatment process for removing residual pharmaceuticals, it is inappropriate for some limited residual pharmaceuticals, such as sulfamethoxazole. It has been reported that sulfamethoxazole is negatively charged at $\mathrm{pH} 6$ or more, which poses difficulties in removal with activated carbon [38]. In this study, as the $\mathrm{pH}$ of the adsorption process was 7 or more, it is considered that the lowest removal efficiency occurs for the same reason reported by EU. 
Trimethoprim is a hydrophilic pharmaceutical whose log $\mathrm{K}_{\text {ow }}$ is 0.91 , and its water solubility is $400 \mathrm{mg} / \mathrm{L}$, showing a relatively high removal efficiency of 57.6\%. The log $\mathrm{K}_{\text {ow }}$ (hydrophobicity and hydrophilicity), solubility, and photoreactivity of antibiotic-based pharmaceuticals has been reported to be subject to change depending on the $\mathrm{pH}$ [40], and the removal efficiency varies greatly depending on the treatment plant and environmental conditions.

The $\log \mathrm{K}_{\mathrm{ow}}$ of diclofenac was 4.02, showing a high adsorption capacity, but the treatment efficiency was low, unlike in the results of previous studies. Therefore, it is considered that further research is needed to address this problem.

\subsection{Suggestion and Application of an Optimal Treatment Process for the Removal of Pharmaceuticals}

The optimum operating conditions of $3 \mathrm{mg} / \mathrm{L}$ ozone, 10-min EBCT, and $30 \%$ activated carbon dosage were derived through spike damage tests in the biological treatment process and ozone and adsorption process on the influent in actual treatment plants. The results of the continuous pilot plant experiments under the optimal conditions are shown in Fig. 7(a). In addition, the optimal treatment conditions for each process were applied, and the application results by process using the actual influent of the treatment plants for 3 months, from September to December 2018, are shown in Fig. 7(b). For sampling, samples were taken from all the processes, including the biological treatment process, considering the hydraulic retention time (HRT), to reduce the error as much as possible.

In the biological process, the concentrations removed from the influent through the anaerobic-anoxic-aerobic reactors were found to be constant for each type, and the removal efficiency of the biological process ranged from 10 to $25 \%$ in the case of high concentrations. Abnormal removal efficiencies as in Table S1 were not observed. However, when the actual influent of the sewage treatment plant in K city was used, the removal efficiency through the biological process was found to be negligible. This result suggests that since micropharmaceuticals are present in extremely small quantities, the biological process has little effect on the removal. It was found that acetaminophen shows a high removal efficiency of more than $96 \%$ in the biological process, but it is difficult to remove other substances through the biological treatment process along. As a result, in the ozone oxidation process, diclofenac showed the highest removal efficiency (57\%) compared to the influent. When pharmaceuticals through the ozone process with an ozone dosage of $3 \mathrm{mg} / \mathrm{L}$ were subjected to continuous adsorption treatment, considering economic efficiency, the removal efficiencies of the final effluent were $98.6 \%$ for acetaminophen, $87.0 \%$ for carbamazepine, $86.0 \%$ for sulfamethoprim, $87.2 \%$ for trimethoprim, and $89.5 \%$ for diclofenac, and all of them showed a high removal efficiency of $85 \%$ or more. In particular, carbamazepine, sulfamethoprim and diclofenac were rarely removed by the biological process alone, but showed the possibility of removal through the introduction of the ozone process. In addition, the stable removal of sulfamethoprim and diclofenac was difficult through either ozone process or adsorption process, but the stable treatment could be expected in the continuous process of ozone-adsorption, which exhibited more than $80 \%$ removal efficiency. Therefore, it is expected that the addition of ozone oxidation and activated carbon adsorption process to the existing sewage treatment process can effectively increase the removal efficiency of micropharmaceuticals. These parameters were applied to the pilot plant, and the results of the pilot plant operation for three months are shown in Fig. 7(b). The concentrations of pharmaceuticals showed a tendency to decrease steadily in the ozone process and the activated carbon adsorption process after the biological process. In the ozone process, about 30 to $60 \%$ of micropharmaceuticals except for acetaminophen were removed, and 10 to $20 \%$ of them were additionally removed in the adsorption process. In the biological process, variations in concentrations were unstable, and the concentrations tended to increase in the final settling basin. However, as the concentrations were low in the ozone process and the adsorption process, the removal efficiency was about 30 to $60 \%$ compared to the influent.

This study suggested the optimal treatment conditions in the actual treatment plant, and presented removal efficiencies. It is difficult, however, to show the constant and stable tendencies of the micropharmaceuticals introduced into the actual treatment plant. Therefore, it is expected that the application of stable parameters experimented on with variations in high concentrations can be utilized as invaluable data for the direction of water quality management. In addition, as the factors influencing the removal of micropharmaceuticals in sewage treatment plants can be affected by various elements, such as the characteristics of each substance, the treatment process employed, the temperature and environ-
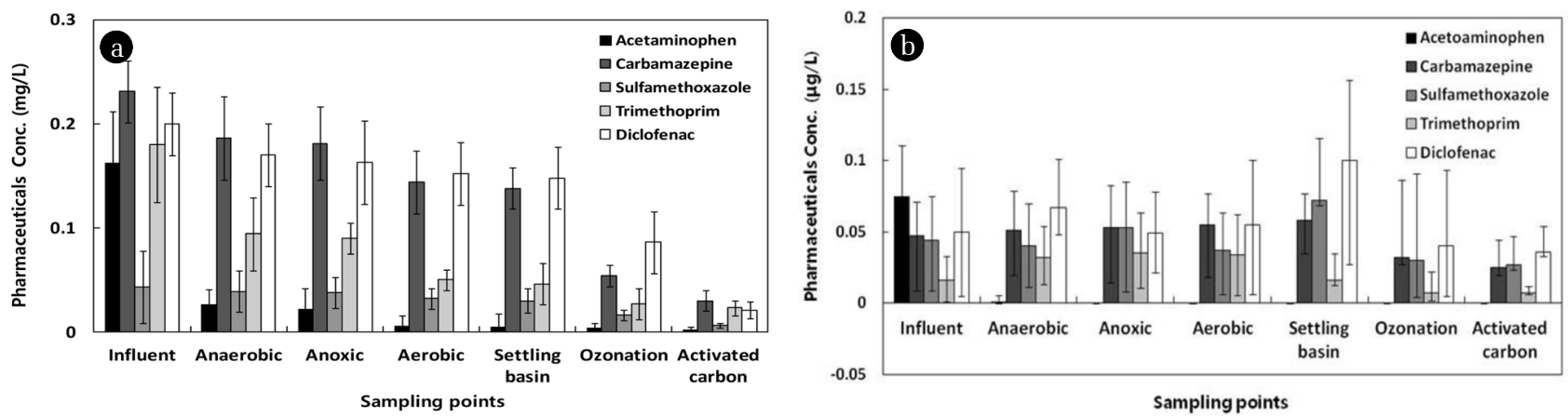

Fig. 7. Pharmaceuticals concentrations at each sampling point in the pilot plant (acetaminophen Conc. $\times 10$ ). (a) With spike damage test. (b) Without spike damage test. 
mental conditions, and the operating status, specific research on the characteristic of the influencing factors is needed to improve the technologies for the management of residual micropharmaceuticals.

\section{Conclusions}

In this study, the research trends of life-based micropharmaceuticals in domestic and overseas sewage treatment plants were investigated, and the current treatment and management status of pharmaceuticals was examined. After that, the variations in the concentrations of the pharmaceuticals in domestic sewage treatment plants were analyzed, and the results of the analysis revealed that it is difficult to treat pharmaceuticals in the biological treatment process. Therefore, an actual pilot plant consisting of the ozone oxidation process and the activated carbon process, which are physicochemical processes performed after the biological treatment process, was installed to investigate the removal efficiencies. In addition, spike damage tests designed to raise the concentrations of micropharmaceuticals were conducted to investigate the variations in the removal efficiencies, and the optimal treatment process that exhibits $80-85 \%$ removal efficiencies of micropharmaceuticals, which are not efficiently removed by the biological treatment process, was proposed through the combination of parameters derived from a single process test. In conclusion, it was confirmed that the stable removal of micropharmaceuticals can be achieved by applying the optimal parameters to the treatment of the influent in the treatment plant to remove $30-60 \%$ of such micropharmaceuticals in the ozone treatment process, and an additional $10-20 \%$ in the adsorption process.

\section{Acknowledgments}

This work was supported by Korea Environment Industry \&Technology Institute (KEITI) through Public Technology Program based on Environmental Policy, funded by Korea Ministry of Environment (MOE)(2016000200008)

\section{References}

1. Korean Health Industry Development Institute. Pharmaceutical Industry Analysis Report; 2017.

2. Korean Ministry of Food and Drug Safety. Food and Drug Statistics Yearbook; 2017.

3. Seo HJ. Study on elimination of residual medicinal substance in standard integer unit process [dissertation]. Gwangju: Chonnam National Univ; 2017.

4. Kum OS. Removal and action of antibiotics in wastewater treatment. Environmental Management Institute; 2011.

5. Jung JE, Lim YS, Cho JG, Kim JI, Lee KS, Yoo PJ. A Survey on Antibiotic Residues in Water Environment in Busan. Report of Busan Institute of Health and Environment; 2014;24:110-122.

6. Beijer K, Björlenius B, Shaik S, Lindberg RH, Brunström B, Brandt I. Removal of pharmaceuticals and unspecified contaminants in sewage treatment effluents by activated carbon filtration and ozonation: Evaluation using biomarker responses and chemical analysis. Chemosphere 2017;176:342-351.

7. Margota J, Kienleb C, Magnetc A, et al. Treatment of micropollutants in municipal wastewater: Ozone or powdered activated carbon? Sci. Total Environ. 2013;461-462:480-498.

8. Antoniou MG, Hey G, Vega SR, et al. Required ozone doses for removing pharmaceuticals from wastewater effluents. Sci. Total Environ. 2013;456-457:42-49.

9. Korean Ministry of Environment. Sewer Statistics; 2016.

10. Gyeongsan City, South Korea. Statistical Yearbook $22^{\text {nd }} ; 2017$.

11. Korean Ministry of Environment. Sewage Design Standard; 2017.

12. Lee S-H. Improvement of biological process and demonstration of technology to improve treatment efficiency of trace amount of harmful substances in bottom and wastewater through filtration type wetland. Environmental Industry Technology Institute; 2018

13. Korean Ministry of Environment. Standard Methods for Testing Wastewater; 2000.

14. Nam SW, Cho KD. Behavior and removal characteristics of trace contaminants in water treatment process. Kor. J. Environ. Health 2013;39:391-407.

15. Stackelberg PE, Gibs J, Furlong ET, Meyer MT, Zaugg SD, Lippincott RL. Efficiency of conventional drinking-water-treatment processes in removal of pharmaceuticals and other organic compounds. Sci. Total Environ. 2007;377:255-272.

16. Jang TS. A Study on the removal rates of medicinal substances and personal dishes in biological sewage treatment plant [dissertation]. Seoul: Univ. of Seoul 2010.

17. Korean Health insurance review and evaluation center healthcare big data open system drug use statistics [Internet]. Wonju: Healthcare Bigdata Hub; [cited June 2018]. Available from: http://opendata.hira.or.kr.

18. Son HJ, Jang SH. Detection, behavior, distribution status and toxicity of residual medicinal substance in water supply. Kor. J. Environ. Eng. 2011;33:453-479.

19. Löffler D, Römbke J, Meller M, Ternes TA. Environmental fate of pharmaceuticals in water/sediment systems. Environ. Sci. Technol. 2005;39:5209-5218.

20. Zhang Y. Geiszen SU, Gal C. Carbamazepine and diclofenac: Removal in wastewater treatment plants and occurrence in water bodies. Chemosphere 2008;73:1151-1161.

21. RxList. The Internet Drug Index [Internet]. San Clemente: RxList; c2006 [cited August 2017]. Available from: http://www.rxlist.com.

22. Yamamoto H, Nakamura Y, Moriguchi S, Nakamura Y, Honda Y, Tamura I. Persistence and partitioning of eight selected pharmaceuticals in the aquatic environment: Laboratory photolysis, biodegradation, and sorption experiments. Water Res. 2009;43: 351-362.

23. Kasprzyk-Hordern B, Dinsdale RM, Guwy AJ. The removal of pharmaceuticals, personal care products, endocrine disruptors and illicit drugs during wastewater treatment ant its impact on the quality of receiving waters. Water Res. 2009;43:363-380.

24. Gobel A, McArdell CS, Joss A, Siegrist H, Giger W. Fate of sulfonamides, macrolides and trimethoprim in different wastewater treatment technologies. Sci. Total Environ. 2007;372:361-371.

25. Zwiener C, Frimmel FH. Short-term tests with a pilot sewage 
plant and biofilm reactors for the biological degradation of the pharmaceutical compounds clofibric acid, ibuprofen, and diclofenac. Sci. Total Environ. 2003;309:201-211.

26. Andreozzi R, Caprio V, Marotta R, Vogna, D. Paracetamol oxidation from aqueous solutions by means of ozonation and $\mathrm{H}_{2} \mathrm{O}_{2} / \mathrm{UV}$ System. Water Res. 2003;37:993-1004.

27. Ikehata K, Jodeiri N, Gamal El-Din NM. Degradation of aqueous pharmaceuticals by ozonation and advanced oxidation processes: A Review. Ozone: Sci. Eng. 2006;28:353-414.

28. Yoon $\mathrm{CH}$. Technology for the treatment of medicinal substances in domestic sewage. Korea Environmental Industry \& Technology Institute; 2014.

29. Korean National institute of environmental research. A study on the investigation and behavior of sources of chemical substances in the environment (IV); 2011.

30. Kim $\mathrm{IH}$. Studies on the removal of medicines by ozone treatment and inactivation of microorganisms. Kor. J. Environ. Eng. 2010;32:1134-1140.

31. Kim KH. Detection status and removal characteristics of medicinal substances in wastewater treatment plant; 2018

32. Huber M, Canonica S, Park GY. Oxidation of pharmaceuticals during ozonation and advanced oxidation processes. Environ. Sci. Technol. 2003;37:1016-1024.

33. Han MS, Choi YW, Song JH, Wang CG. Ozone oxidation removal of trace residue antibiotics in water. Kor. J. Environ. Eng.
2018;34:149-156.

34. Son SS. Advanced technology for treatment of water by activated carbon filtration. In: 2nd International Symposium on Joint Environmental Symposium on Advanced Water Treatment. Gyeongsan: Yeungnam Univ. 1994. p. 159-181.

35. Hong SH, Han GH, Lee CH, Lee SH. Removal of phthalate esters in advanced water treatment unit process. Kor. J. Environ. Eng. 2005;27:461-467.

36. Clara M, Strenn B, Kreuzinger N. Carbamazepine as a possible anthropogenic marker in the aquatic environment: Investigations on the behavior of carbamazepine in wastewater treatment and during groundwater infiltration. Water Res. 2004;38:947-954.

37. Stamatelatou K, Frouda C, Fountoulakis MS, Drillia P, Kornaros M, Lyberatos G. Pharmaceuticals and health care products in wastewater effluents: the example of carbamazepine. Water Sci. Technol. Water Supply 2003;3:131-137.

38. Rogers HR. Sources, behavior and fate of organic contaminants during sewage treatment and in sewage sludges. Sci. Total Environ. 1996;185:3-26.

39. Korean National Institute of Food and Drug Safety Evaluation. Toxicity information providing system [Internet]. Chungju: Tox-Info [October 2018]. Available from: http://www.nifds.go.kr/toxinfo/.

40. Kummerer K. Antibiotic in the aquatic environment-A review-Part 1. Chemosphere 2009;75:417-434. 